\title{
Transthoracic echocardiography in patients with chronic kidney disease
}

\section{Shrestha $B^{1}$, Gurung $D^{2}$, Dhungel $S^{3}$}

'Balaram Shrestha, Professor; Department of Medicine, KIST Medical College Teaching Hospital, Lalitpur; ${ }^{2}$ Dhiraj Gurung, Lecturer; Department of Medicine, Karnali Academy of Health Sciences, Karnali; ${ }^{3}$ Sanjib Dhungel, Professor; Department of Medicine, Nepal Medical College Teaching Hospital, Attarkhel, Kathmandu, Nepal.

\begin{abstract}
Background: Evaluation of cardiac diseases in chronic kidney disease has been rarely investigated in Nepal. Objectives: Objective of this study is to evaluate cardiac lesions in admitted chronic kidney disease patients. Methodology: It is a prospective observational study of echocardiography of chronic kidney disease patients from April, 2007 to April, 2013 in Nepal Medical College Teaching Hospital.

Results: One hundred chronic kidney disease patients were evaluated. Male to Female ratio was 1.8:1 and age \pm SD was $46.3 \pm 17.2$ years. Forty eight percent of the chronic kidney disease patients had left ventricular hypertrophy. Patients with chronic kidney disease with left ventricular hypertrophy group had interventricular septum of $1.5 \pm 0.3 \mathrm{~cm}$ vs. $1.1 \pm 0.1$ $\mathrm{cm}(p<0.0001)$ and posterior wall of $1.1 \pm 0.2 \mathrm{~cm}$ vs. $1.0 \pm 0.1 \mathrm{~cm}(\mathrm{p}<0.01)$ in comparison to chronic kidney disease without left ventricular hypertrophy. Forty one percent had left ventricular systolic dysfunction with left ventricular ejection fraction of $39 \pm 9.9 \%$. Pulmonary arterial hypertension was noticed in 39\% patients. Valvular regurgitant lesions were quite common (241\%) usually as multivalvular lesions (4.4 lesions per patient). Mitral regurgitation was the commonest regurgitant lesion (81\%).

Conclusion: Echocardiographic cardiac evaluation is useful to diagnose concomitant cardiac lesions for standard care of chronic kidney disease patients.
\end{abstract}

Key words: Chronic kidney disease (CKD); Echocardiography; Left ventricular hypertrophy (LVH); Left ventricular systolic dysfunction (LVSD); Valvular lesions

DOI: https://doi.org/10.3126/jkmc.v8i1.25265

\section{INTRODUCTION}

TTorldwide prevalence of chronic kidney disease (CKD) has been estimated to be $8-16 \%{ }^{1}$. Renal diseases are quite common in Nepal. With a population of 27 million people, the estimated incidence of end stage renal disease (ESRD) is around 2700 per year if we take 100 cases of ESRD /million population at par with India and Pakistan², whereas the community based prevalence of CKD in eastern Nepal was found to be $10.6 \%$. The incidence of ESRD has increased gradually with 3.4 per million populations (pmp) in 1990 to 11.89 pmp in 1999 with an average annual incidence of 6 pmp

Address for correspondence

Prof. Dr. Balaram Shrestha

Professor, Department of Medicine

KIST Medical College Teaching Hospital, Lalitpur, Nepal

E-mail: profdrbalaramshresthakist@gmail.com and only $0.31 \%$ of expected ESRD patients received renal replacement therapy ${ }^{4}$.

Renal parenchymal disease is the most common cause of secondary hypertension ${ }^{5,6}$. Hypertension leads to hypertensive heart disease, which is the result of structural and functional adaptations leading to left ventricular hypertrophy (LVH), congestive heart failure, abnormalities of blood flow due to atherosclerotic coronary artery disease, microvascular disease and cardiac arrhythmias ${ }^{5}$. Chronic kidney disease is associated with an eight to tenfold increase in cardiovascular mortality ${ }^{7}$. So, cardiac evaluation of CKD patients is important. Objective of this study is to evaluate the cardiac abnormalities in admitted CKD patients.

Echocardiography provides a non invasive assessment of left ventricular structure and function. Echocardiography based evaluation of cardiac 
abnormalities in CKD patients are available from various international centers ${ }^{8-15}$, but it is quite rare in Nepal ${ }^{16}$. Here, we present our prospective study of echocardiography based evaluation of cardiac abnormalities in admitted CKD patients.

\section{METHODOLOGY}

This is a prospective observational study of admitted CKD patients undergoing transthoracic echocardiography during sixyears period from 2007 to 2013 in Nepal Medical College Teaching Hospital Echocardiography laboratory (NMCTH echo lab). Diagnosis of different stages of CKD has been done as per previous recommendation ${ }^{5}$ with CKD stage I as estimated glomerular filtration rate $>90$ $\mathrm{mL} / \mathrm{min}$ per $1.73 \mathrm{~m}^{2}$, stage II as $60-89$, stage III as $30-59$, stage IV as $15-29$ and stage $V$ as $<15$.

The decisions to do or not do echocardiography were as per the clinical judgments of the treating nephrologists/ physicians. Patients $>16$ years to $\leq 80$ years with CKD of various stages under hemodialysis or not under hemodialysis were included in the study. Patients with presence of pre-existing heart disease, e.g. Rheumatic heart disease, diagnosed valvular lesions, arrhythmias were excluded from the study

Echocardiography machines used for this study were LOGIQ 400 MD MR3 Version 4.31 (GE, USA) and Toshiba Nemio XD (Tokyo, Japan). Evaluation of various cardiac parameters such as left ventricular ejection fraction (LVEF), left ventricular diastolic dysfunction (LVDD), left ventricular hypertrophy (LVH), valvular lesions and pericardial effusion were evaluated for this study. Echocardiographic findings were presented as one abnormality as one entity (e.g. one patient with 4 valvular regurgitant lesions, LVH, LVDD, PAH are collectively considered as 7 lesions) and one cardiac disease as one entity (e.g. one patient with 4 valvular regurgitant lesions, LVH, LVDD, PAH are collectively considered as one valvular lesion and not each lesion as one separate entity).

Teichholz method was used for calculation of LVEF per the local availability of this system in echocardiographic machines in $\mathrm{NMCTH}^{17}$. With Teichholz formula ${ }^{18}$, LVEF is calculated by dividing stroke volume (SV) in the LV outflow tract (LVOT), by end-diastolic volume (LVEDV) ${ }^{7}$.

$$
\begin{aligned}
& \mathrm{SV}=\Pi \mathrm{X} \frac{\left(\text { LVOT }^{2} \mathrm{X} \mathrm{VTI}_{1}\right.}{2} \\
& \mathrm{LVEDV}=\frac{\left(7 \mathrm{X} \mathrm{LVEDD}^{3)}\right.}{\left(2.4+\text { LVEDD }^{2}\right)}
\end{aligned}
$$

$\mathrm{LVEF}=\mathrm{SV} / \mathrm{LVEDV}$

[LVEDD: LV end-diastolic dimension

LVOT: Left ventricular outflow tract diameter

$\mathrm{VTI}_{1}$ : LVOT subvalvular velocity time integral

SV: Stroke volume

LVEDV: LV end-diastolic volume

LVEF: LV ejection fraction (\%)]

Left ventricular wall thickness $>1.3 \mathrm{~cm}$ is unusual in physiological hypertrophy ${ }^{19}$. Interventricular septum (IVS) and posterior wall (PW) thickness of 1.3 to $1.5 \mathrm{~cm}$ have been recommended as moderate hypertrophy in women and 1.4 to $1.6 \mathrm{~cm}$ as moderate hypertrophy (1.1 to $1.3 \mathrm{~cm}$ as mildly abnormal) in men ${ }^{20}$.

LVEF less than $55 \%$ was considered as low in this study ${ }^{21,22}$ sub-grouping ejection fraction of $45-54 \%$ as mild systolic dysfunction, $30-44 \%$ as moderate systolic dysfunction and less than $30 \%$ as severe systolic dysfunction ${ }^{21,22}$. The LVDD was diagnosed as previous criteria ${ }^{13,23}$. We have used simple criteria of tall left ventricular inflow A wave in comparison to $E$ wave to detect LVDD ${ }^{13,23}$.

Estimated systolic pulmonary artery pressure (PAP) has been calculated with tricuspid regurgitation (TR) based trans-tricuspid pressure gradient [4 $\mathrm{V}^{2}$ of TR velocity (V)] + right atrial pressure (RAP). Right atrial pressure was empirically fixed as $10 \mathrm{~mm} \mathrm{Hg}{ }^{24,25}$. The PAH was subgrouped into mild $\mathrm{PAH}(36-45 \mathrm{~mm} \mathrm{Hg})$, moderate $\mathrm{PAH}$ (46-60 mm Hg) and severe PAH (>60 mm Hg) ${ }^{24,25}$.

Data were presented as Mean \pm SD. Unpaired t-test was performed where appropriate and $p<0.05$ was considered significant. Microsoft Excel 2007 was used for the calculations.

\section{RESULTS}

Altogether 100 admitted CKD patients underwent transthoracic echocardiography during the study period of six years. Out of them, male to female ratio was 1.8:1 and mean age \pm SD was $46.3 \pm 17.2$ years.

Evaluation of echocardiography based cardiac lesions is shown in Figure 1. Valvular heart diseases were present in $60 \%$ CKD patients in one disease one entity presentation. In one abnormality one entity presentation, altogether there were 440 cardiac lesions (440\%) detected in 100 CKD patients as shown in Figure 1. Regurgitant valvular lesions were the most common findings (241\%) in the echocardiography. Mitral regurgitation was the most common regurgitant lesion (81\%), followed by tricuspid regurgitation (76\%) and aortic regurgitation (38\%) as shown in Figure 1. 
Comparison of presence or absence of LVH is shown in Table 1. Left ventricular hypertrophy was noticed in $48 \%$ of the CKD patients. Compared to the non-LVH group, the LVH group had IVS of $1.5 \pm 0.3 \mathrm{~cm}$ vs. $1.0 \pm 0.2 \mathrm{~cm}$ (p $<0.0001)$ and PW of $1.1 \pm 0.2 \mathrm{~cm}$ vs. $0.9 \pm 0.3 \mathrm{~cm}(p<0.01)$.

LV wall thickness (Interventricular septum, IVS and Posterior wall, PW) in $\mathrm{cm}$ has been shown in Table 2, according to various grades of CKD. There were nonsignificant difference in IVS thickness $(p=0.18$, nonsignificant) and PW thickness ( $p=0.04$, significant) when CKD IV and V were compared.

Comparison of presence or absence of low ejection fraction in CKD patients is shown in Table 3. Forty one percent had left ventricular systolic dysfunction (LVSD) with LVEF of $39.5 \pm 9.9 \%$ vs. $63.4 \pm 6.4 \%(p<0.0001)$ in comparison to CKD patients without LVSD. Various grades of LVSDs are shown in Table 4 with 19\% patients were having moderate LVSD.
LVEF according to various CKD grades are shown in Table 5. There were non-significant difference of LVEF between CKD stage IV (LVEF $=52.5 \pm 9.5 \%)$ and CKD stage $V$ had LVEF of $50.9 \pm 18.1 \%(p=0.67, N S)$.

Pulmonary arterial hypertension (PAH) in CKD patients is shown in Table 6. Thirty nine percent of CKD patients had PAH out of which, $18 \%$ had mild PAH. Estimated pulmonary arterial hypertension in various grade of CKDs are shown in Table 7 with non-significant tendency of rising PAP with worsening grades of CKD.

(AR-aortic regurgitation; MR-mitral regurgitation; TRtricuspid regurgitation; PR-pulmonary regurgitation; LVH-Left ventricular hypertrophy; PAH-Pulmonary arterial hypertension; PE-pericardial effusion; LVSD-Left ventricular systolic dysfunction; LVDD-Left ventricular diastolic dysfunction)

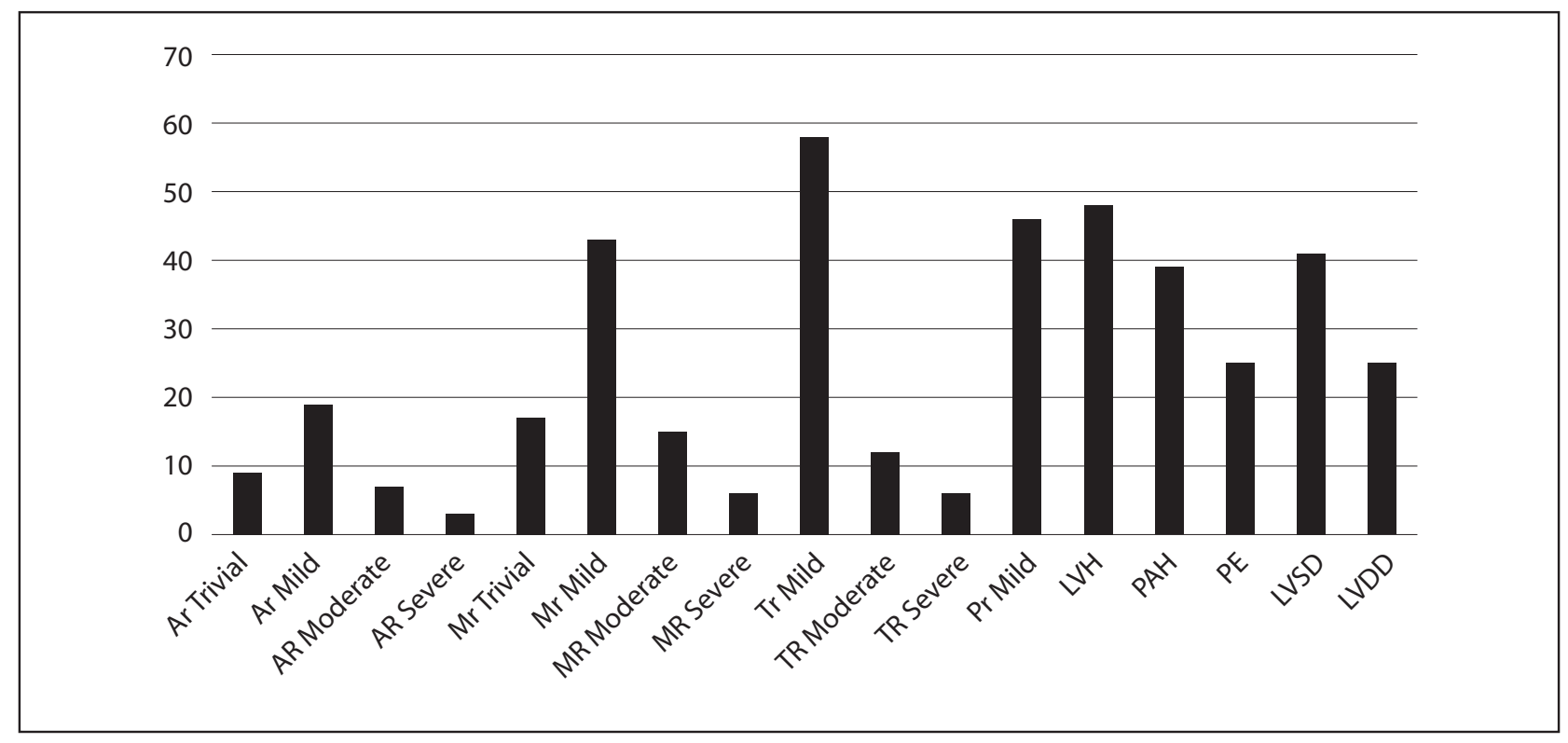

Figure 1: Echocardiographic findings in CKD patients

Table 1: Left ventricular wall thickness in CKD patients with and without LVH

\begin{tabular}{lllcc}
\hline LVH & IVS: Mean \pm SD (Range) & PW: Mean \pm SD (Range) & Frequency & (\%) \\
\hline LVH & $1.5 \pm 0.3 *(1.3$ to $2.7 \mathrm{~cm})$ & $1.1 \pm 0.2 \#(0.8$ to $1.8 \mathrm{~cm})$ & 48 & 48 \\
No LVH & $1.0 \pm 0.2 *(0.7$ to $1.2 \mathrm{~cm})$ & $0.9 \pm 0.3 \#(0.7$ to $1.3 \mathrm{~cm})$ & 52 & 52 \\
\hline$* \mathrm{p}<0.0001$ & & & & \\
$\# \mathrm{p}<0.01$ & & &
\end{tabular}


Table 2: IVS and PW thickness according to various grades of CKD $(n=100)$

\begin{tabular}{|ccccc|}
\hline CKD grades & IVS (Mean \pm SD) (Range) & PW (Mean \pm SD) (Range) & Frequency & (\%) \\
\hline CKD V & $1.3 \pm 0.3^{*}(0.7$ to $1.9 \mathrm{~cm})$ & $1.1 \pm 0.2 \#(0.7$ to $1.6 \mathrm{~cm})$ & 88 & 9 \\
\hline CKD IV & $1.5 \pm 0.6^{*}(0.8$ to $2.7 \mathrm{~cm})$ & $1.2 \pm 0.3 \#(1$ to $1.8 \mathrm{~cm})$ & 2 & 2 \\
\hline CKD III & $1.2(1.1$ to $1.2 \mathrm{~cm})$ & $1(0.8$ to $1.1 \mathrm{~cm})$ & 1 & 1 \\
\hline CKD I & $1 \mathrm{~cm}$ & $1.1 \mathrm{~cm}$ & 1 \\
\hline
\end{tabular}

* $p=0.18$ (NS)

$\# p=0.04$

(IVS: Interventricular septum; PW: Posterior wall).

Table 3: Presence or absence of low ejection fraction in CKD patients

\begin{tabular}{|cccc}
\hline LVEF & Mean \pm SD $($ range $)$ & Frequency & (\%) \\
\hline Low LVEF & $39.5 \pm 9.9 *(53.6$ to $19.8 \%)$ & 41 & 41 \\
Good LVEF & $63.4 \pm 6.4 *(79.9$ to $55 \%)$ & 59 & 59 \\
\hline
\end{tabular}

${ }^{*} \mathrm{p}<0.0001$

Table 4: Systolic dysfunction in CKD $(n=100)$

\begin{tabular}{|c|c|c|c|}
\hline Grades of LVEF & $\begin{array}{l}\text { Grades of systolic } \\
\text { dysfunction }\end{array}$ & Frequency & (\%) \\
\hline$>=55 \%$ & Normal & 59 & 59 \\
\hline $45-54 \%$ & Mild & 16 & 16 \\
\hline $30-44 \%$ & Moderate & 19 & 19 \\
\hline$<30 \%$ & Severe & 6 & 6 \\
\hline
\end{tabular}

Table 5: LVEF according to various CKD grades $(n=100)$

\begin{tabular}{|cccc}
\hline CKD grades & LVEF (\%) (Mean \pm SD) (Range) & Number & $(\%)$ \\
\hline CKD V & $50.9 \pm 18.1^{*}(25$ to 79.9$)$ & 88 & 88 \\
CKD IV & $52.5 \pm 9.5^{*}(43$ to 65$)$ & 9 & 9 \\
\hline CKD III & $65.5(53.6$ to 77.3$)$ & 2 & 2 \\
CKD I & $61(61)$ & 1 & 1 \\
\hline
\end{tabular}

${ }^{*} p=0.67(N S)$

Table 6: Pulmonary arterial hypertension in CKD $(\mathbf{n = 1 0 0 )}$

\begin{tabular}{|cccc|}
\hline Grades of PAH & PAH grades & Frequency & (\%) \\
\hline$<35$ & Normal & 61 & 61 \\
\hline $36-45$ & Mild PAH & 18 & 18 \\
\hline $46-60$ & Moderate PAH & 13 & 13 \\
$>60$ & Severe PAH & 8 & 8 \\
\hline
\end{tabular}

Table 7: Pulmonary arterial hypertension in various grades of CKD

\begin{tabular}{|cccc}
\hline CKD grades & PAH $(\mathbf{m m ~ H g})($ Mean \pm SD) (Range) & Frequency & $(\%)$ \\
\hline CKD V & $51.1 \pm 16.3(28.6$ to 90.4$) *$ & 88 & 88 \\
CKD IV & $43.9(41.2$ to 46.6$) *$ & 9 & 9 \\
\hline CKD III & $46(44$ to 48$)$ & 2 & 2 \\
CKD I & $32.3(32.3)$ & 1 & 1 \\
\hline
\end{tabular}

${ }^{*} p=0.17$ (NS) 


\section{DISCUSSION}

In this prospective study of a small group of admitted 100 CKD patients attending NMCTH-echo lab during six years period, male to female ratio was 1.8:1. Similar male predominance in Nepalese population has been reported by several other authors as well ${ }^{26,27}$ reporting approximately $65 \%$ male patients. In our male dominated society, males get more treatment especially when it is expensive $^{27}$. In one study, one- third of the CKD patients (37\%) had to sell their property for the treatment ${ }^{27}$.

Poverty and lack of female awareness may have contributed to less female referral to tertiary care centres for better CKD management. Mean age (age \pm SD, $46.3 \pm 17.2$ years) of CKD patients was similar to previous study ${ }^{28}$. Echocardiography provides a noninvasive assessment of systolic and diastolic function of left ventricle. It is also very useful in evaluation of the presence of LVH and its severity $8,12,14,15$.

The incidence of LVH increases with progressive decline in renal function ${ }^{29}$. It was noticed in $48 \%$ of the CKD patients undergoing echocardiography. Patients with CKD with LVH group had IVS of $1.5 \pm 0.3 \mathrm{~cm}$ vs. $1.0 \pm 0.2$ $\mathrm{cm}, \mathrm{p}<0.0001$ ) and PW of $1.1 \pm 0.2 \mathrm{~cm}$ vs. $0.9 \pm 0.3 \mathrm{~cm}, \mathrm{p}<$ 0.01 ) in comparison to CKD without LVH. There was nonsignificant difference in degree of hypertrophy in CKD IV $(1.5 \pm 0.6$ vs $1.3 \pm 0.3(p=0.18, N S)$ as compared to CKD $\mathrm{V}(1.2 \pm 0.3$ vs $1.1 \pm 0.2(p=0.04$, Significant $)$ as shown in Table 2.

Individuals with LVH are at increased risk for coronary heart disease (CHD), stroke, congestive heart failure, and sudden death. Aggressive control of hypertension can regress or reverse $\mathrm{LVH}$ and reduce the risk of cardiovascular disease ${ }^{5}$.

Good BP control in general Nepalese hypertensive was noted $(19.0 \%)^{30}$ and in CKD patients, it was noted in $31.4 \%$. The control of BP in these CKD patients had been poor. In comparison to intensive BP controlled group, uncontrolled group received more antihypertensive agents $(3.0 \pm 1.3 \text { vs. } 2.0 \pm 0.8, p<0.05)^{31}$.

Echocardiography is a very valuable noninvasive tool found to be extremely useful in the evaluation of left ventricular systolic function (LVSD). In this study, 41\% of the patients had LVSD. This finding is higher than previous report of $13.2 \%{ }^{16}$. One cause for it may be inclusion of LVEF $<55 \%$ as LV systolic dysfunction. However, our data is similar to pre-transplant data reported elsewhere ${ }^{32}$.
Patients with CKD with LVSD had LVEF of $39.5 \pm 9.9 \%$ vs. $63.4 \pm 6.4 \%(p<0.0001)$ in comparison to CKD without LVSD. Left ventricular ejection fraction, in CKD stage IV $52.5 \pm 9.5$ vs $50.9 \pm 18.1 \%(p=0.67, N S)$, as compared with CKD stage $V$, was not statistically significant.

Valvular lesions were present in 60\% CKD patients in one disease one entity presentation. In one disease one entity presentation, regurgitant valvular lesion were common findings (241\%) in the echocardiography. Mitral regurgitation being the most common (81\%) lesion, was followed by TR (76\%) and AR (38\%). Cause for having excessive regurgitant lesion may be due to the inclusion of trivial or minimal regurgitant lesions. These trivial regurgitant lesions may be normal findings. This higher proportion of valvular lesions may also be due to selection bias, selecting clinically more symptomatic patients with the higher probability of having various cardiac lesions inclusive of regurgitant lesions for echocardiographic evaluation. All of these valvular lesions are unlikely to be directly related to CKD. Causes like hypervolemic status in CKD, chamber dilation, annular dilation and mitral annular calcification may have at least partly contributed to regurgitant lesions such as MR and AR. Presence of significant regurgitant lesions in CKD may have contributed to the significant left ventricular systolic dysfunction in this study. When meticulously searched in general population, MR can be detected in $70-80 \%$, TR in $80-90 \%$ and PR in 70$80 \%$ without clarifying whether it is trivial or mild regurgitation ${ }^{33}$. Aortic regurgitation is rare in normal individuals that is present in $5 \%$ in young individuals with increasing prevalence of AR with age.

The left ventricular diastolic dysfunction (LVDD) was noticed in 25 patients (25\%) in this study. This finding is less than the other report of left ventricular diastolic dysfunction in $58.5 \%{ }^{16}$. They may have used various techniques to better detect LVDD without elaboration. We have used simple technique to detect LVDD which may pick up LVDD stage I and miss equivocal cases and LVDD stage III. This may have resulted in less LVDD.

The $\mathrm{PAH}$ is highly prevalent in end-stage renal disease. Several observational studies based on an echocardiographic diagnosis of $\mathrm{PAH}$, have suggested a prevalence of $30-60 \%$ and an association with increased mortality and poorer outcome following renal transplantation ${ }^{34}$. In this study, PAH was noticed in about one third of patients (39\%). In CKD patients under hemodialysis, usually have hypervolemic state, resulting in increased stroke volume, increased right ventricular output and increased pulmonary artery pressure. As 
hypertension is very common comorbid condition, it may have resulted in deterioration in left ventricular systolic dysfunction and pulmonary arterial pressure. In our study, there was non-significant but rising trend in pulmonary arterial hypertension in severe CKD stage as compared to milder CKD stages. Further study is necessary with more patients to achieve the statistically significant interpretation.

Data related to distribution of various grades of $\mathrm{PAH}$ were a bit higher than the report of 2351 Chinese CKD patients ${ }^{35}$, with mild (12.1\%) and moderate PAH (4.9\%). The cause of this discrepancy is not known. The difference in ethnicity may have played a role. They have reported pulmonary hypertension, PAH in CKD being associated with cardiac morbidity and stated as increasing cardiac morbidity were seen with increasing $\mathrm{PH}$ severity ${ }^{35}$.

In this study, pericardial effusion was detected in $25 \%$ of CKD patients. In comparison to one previous study,

\section{REFERENCES}

1. Jha V, Garcia-Garcia G, Iseki K, Li Z, Naicker S, Plattner B et al. Chronic kidney disease: global dimension and perspectives. Lancet. 2013 Jul 20;382(9888):260-72. [DOI]

2. Khakurel S, Agrawal RK, Hada R. Pattern of end stage renal disease in a tertiary care center. J Nepal Med Assoc 2009 Apr-Jun;48(174):126-30. [PubMed]

3. Sharma SK, Dhakal S, Thapa L, Ghimire A, Tamrakar $R$, Chaudhary S, et al. Community -based screening for chronic kidney disease, hypertension and diabetes in Dharan. J Nepal Med Assoc. 2013 JanMar;52(189):205-12. [PubMed]

4. Hada R, Khakurel S, Agrawal RK, Kafle RK, Bajracharya $S B$. Raut KB. Incidence of end stage renal disease on renal replacement therapy in Nepal. Kathmandu Univ Med J. 2009 July-Sep;7(27):301-5. [PubMed]

5. Victor G. Systemic Hypertension: Mechanisms and Diagnosis. In, Bonow RO, Mann DL, Zipes DP, Libby P, ed. Braunwald's Heart Disease: A Textbook of Cardiovascular Medicine. $9^{\text {th }}$ ed. Philadelphia: Saunders an imprint of Elsevier 2012:935-54 p.

6. Kotchen TA. Hypertensive Vascular Disease, In Longo DL, Fauci AS, Kasper DL, hauser SL, Jameson $\mathrm{JL}$, Loscalzo J, ed. Harrison's Principles of Internal Medicine $18^{\text {th }}$ ed.New York: McGraw Hill Medical 2012: 2042-59 p.

7. Couser WG, Remuzzi G, Mendis S, Tonelli M. The contribution of chronic kidney disease to the global out of 50 end stage renal disease patients ${ }^{16}, 32.1 \%$ were reported to have pericardial effusion. This data is nominally higher than our findings. In asymptomatic CKD patients (35 ERSD patients), 11\% had pericardial effusion with $6 \%$ having effusion $>100 \mathrm{ml}$. However, in symptomatic ERSD patients with symptoms of pericarditis, $51 \%$ had pericardial effusion ${ }^{36}$. As our study did not discriminate for symptomatic or nonsymptomatic CKD patients, our effusion data is reasonable. In another paper, $32.1 \%$ patients were reported to have pericardial effusion ${ }^{16}$.

\section{CONCLUSION}

The high prevalence of left ventricular systolic dysfunction, left ventricular hypertrophy, pulmonary arterial hypertension and regurgitant valvular lesions in this study with CKD patients is important and useful information while dealing with the clinical problems in CKD patients. It is recommended for CKD patients to undergo echocardiographic evaluation of co-morbid cardiac conditions such as LVSD, LVDD and LVH.

burden of major noncommunicable diseases. Kidney Int. 2011 Dec; 80(12): 1258-70. [PubMed]

8. Foley RN, Parfrey PS, Kent GM, Harnett JD, Murray DC, Barre PE et al. Clinical and echocardiographic disease in patients starting end-stage renal disease therapy. Kidney International, 1995;47:186-92. [PubMed]

9. Matsumoto M, lo H, Furukawa M, Okumura K, Masuda A, Seto T et. al. Risk factors associated with increased left ventricular mass index in chronic kidney disease patients evaluated using echocardiography. J Nephrol. 2012 Sep-Oct;25(5):794-801. [DOI]

10. Ahmed A, Rich MW, Sanders PW, Perry GJ, Bakris GL, Zile MR et. al. Chronic kidney disease associated mortality in diastolic versus systolic heart failure: a propensity matched study. Am J Cardiol. 2007 Feb;99(3):393-8. [PubMed]

11. Wanic-Kossowska M, Lehmann $P$, Czekalski S. Left ventricular systolic and diastolic dysfunction in patients with chronic renal failure treated with hemodialysis. Pol Arch Med Wewn. 2003 Apr;109(4):365-73. [PubMed]

12. Chen SC, Chang JM, Liu WC, Huang JC, Tsai JC, Lin $M Y$ et al. Echocardiographic parameters are independently associated with increased cardiovascular events in patients with chronic kidney disease. Nephrol Dial Transplant 2012 Mar;27(3):1064-70. [DOI]

13. Rathod NR, Ghodasara MK, Shah HD. Assessment of cardiac dysfunction by $2 \mathrm{D}$ echocardiography in 
patients of chronic kidney disease. J pharmaceutical biomed sci. 2012;17:1-6. [DOI]

14. Lesaffre F, Wynckel A, Nazeyrollas P, Rieu P, Metz D. Echocardiography to predict adverse cardiac and vascular events I patients with severe chronic kidney disease (stage 4): a prospective study. Arch Cardiovasc Dis. 2-13 April;106(4):220-7. [DOI]

15. Stallworthy EJ, Pilmore HL, Webster MW, Sidhu KK, Curry EM, Brown P et al. Do echocardiographic parameters predict mortality in patients with end-stage renal disease? Transplantation. 2013 May;95(10):1225-32. [DOI]

16. Roka K, Roka PB. Clinical Manifestations of Cardiac Disease in Patients with End Stage Renal Disease Under Maintenance Hemodialysis in a Tertiary Level Hospital of Nepal. MJSBH. 2016 July; 15 ( 1 ): 61-5. [DOI]

17. Toshiba Medical Systems Corporation. Left Ventricular Function Measurement (LV) In, Operation Manual for Diagnostic Ultrasound System: Nemio XG Japan. 2006:3/6-3/12. [Full Text]

18. Dumesnil JG, Dion D, Yvorchuk K, Davies RA. Chan K. A new, simple and accurate method for determining ejection fraction by Doppler echocardiography. Can J Cardiol. 1995 Dec;11(11):1007-14. [PubMed]

19. Feigenbaum $H$, Armstrong WF, Ryan $T$, Evaluation of Systolic and Diastolic Function of the Left Ventricle In, Feigenbaum's Echocardiography. $6^{\text {th }}$ ed. Philadelphia: Lippincott Williams \& Wilkins 2005: 138-81p.

20. Oh JK, Seward JB, Tajik AJ. The Echo Manual.3rd ed.New Delhi: Lippincott Williams \& Wilkins 2006;401-15p.

21. Lang RM, Bierig $M$, Devereaux RB, Flachskampf FA, Foster E, Pellikka PA et al. Chamber Quantification Writing Group, American Society of Echocardiography's Guidelines and Standards Committee, European Association of Echocardiography. Recommendations for chamber quantification: A report from the American Society of Echocardiography's Guidelines and Standards Committee and the Chamber Quantification Writing Group, developed in conjunction with the European Association of Echocardiography, a branch of European Society of Cardiology. J Am Soc Echocardiogr. 2005 Dec;18(12):1440-63. [PubMed]

22. Farshid A, Pathak R, Shadbolt B, Armolda L, Talaulikar G. Diastolic function is a strong predictor of mortality in patients with chronic kidney disease. [Internet] BMC Nephrol. 2013 Dec 23;14:280. Available from: http://www.biomedcentral.com/1471-2369/14/280 [Accessed on 22 ${ }^{\text {nd }}$ June 2014]. [PubMed]
23. Vlahoviæ A, Popoviæ AD. Evaluation of left ventricular diastolic function using Doppler echocardiography. Med Pregl. 1999 JanFeb;52(1-2):13-8. [PubMed]

24. Porter BS. Pulmonary hypertension. In, Wong CJ, Hamlin NP, editor. The Perioperative Medicine Consult Handbook. Washington: Springer 2013: 101-8 p.

25. Reddy YNV, Lanawat D, Abraham G, Matthew M, Mullasari A, Nagarajan $P$ et al. Progressive pulmonary hypertension: Another criterion for expeditious renal transplantation. Saudi J Kindey Dis Transpl. 2013 Feb;24(5):925-9. [PubMed]

26. Sigdel MR, Pradhan RR. Chronic Kidney Disease in a Tertiary Care Hospital in Nepal. J Inst Med. 2018 August;40:2:104-11. [DOI]

27. Mishra D, Koirala P. Status of Chronic Kidney Disease Patients Registered in National Kidney Center, Banasthali, Kathmandu. J Manmohan Inst Health Sci. 2015 Feb;1(4):19-23. [DOI]

28. Chhetri PK, Manandhar DN, Bhattarai SP, Pahari LR, Shrestha R. Chronic kidney disease 5 on hemodialysis in Nepal Medical College Teaching Hospital. Nepal Med Coll J 2008 March;10(1):8-10. [PubMed]

29. Cerasola G, Nardi E, Palermo A, Mulè G, Cottone S. Epidemiology and pathophysiology of left ventricular abnormalities in chronic kidney disease: a review. J Nephro 2011 Jan-Feb;24(1):1-10. [PubMed]

30. Dhungel S, Shrestha A, Bhattarai P, Paudel B. Study of cases of hypertension admitted at Nepal Medical College Teaching Hospital. Nepal Med Coll J. 2004 June;6(1):36-8. [PubMed]

31. B Shrestha, S Dhungel. Evaluation of control of blood pressure in chronic kidney disease patients with hypertension attending echo-lab of Nepal Medical CollegeTeaching Hospital. Nepal Med Coll J. 2012 Jun; 14(2): 118-24. [PubMed]

32. Casas-Aparicio G, Castillo-Martínez L, Orea-Tejeda A, Abasta-Jiménez $M$, Keirns-Davies $C$, RebollarGonzález V. The effect of successful kidney transplantation on ventricular dysfunction and pulmonary hypertension. Transplant Proc. 2010 Nov;42(9):3524-8. [DOI]

33. Otto CM. Valvular Regurgitation In, Otto CM. Textbook of Clinical Echocardiography. $5^{\text {th }}$ ed. Philadelphia: Saunders An imprint of Elsevier 2013: 305-41 p.

34. Movva R, Murthy K, Romero-Corral A, Seetha Rammohan HR, Fumo P, Pressman GS. Calcification of the mitral valve and annulus: systematic 
evaluation of effects on valve anatomy and function. J Am Soc Echocardiogr. 2013 Oct;26(10):1135-42. [DOI]

35. Li Z, Liang X, Liu S, Ye Z, Chen Y, Wang W et al. Pulmonary Hypertension: Epidemiology in Different CKD stages and its association with Cardiovascular
Morbidity. PLoS ONE 2014 Dec 19; 9(12): e114392. Doi:10.1371/journal.pone.0114392. eCollection 2014. [Accessed on $2^{\text {nd }}$ April 2019]. [DOI]

36. Kleiman JH, Motta J, London E, Pennell JP, Popp RL. Pericardial effusions in patients with end-stage renal disease. Br Heart J.1978 Sep;40(2): 190-3. [DOI] 